\title{
Automatic and controlled processes in the first- and second-language reading of fluent bilinguals
}

\author{
MICHELINE FAVREAU and NORMAN S. SEGALOWITZ \\ Concordia University, Montreal, Quebec, Canada
}

\begin{abstract}
Many fluent bilinguals read their two languages with equal levels of comprehension but read their second language at a slower rate. The present study examined whether, compared with firstlanguage reading, slower second-language reading is associated with reduced involvement of automatic processing during lexical access. Subjects were bilinguals with fluent speaking and listening skills under ordinary conditions of communication and with equivalent comprehension of their first and second languages when reading and listening under speded conditions. Half these subjects, however, read their first and second languages equally fast, and half read the second language more slowly than the first. Subjects were tested on a lexical decision task that manipulated expectations about the semantic relatedness of prime and target words and the stimulus onset asynchrony between them. Bilinguals with equal first- and second-language reading rates produced in each language a pattern of reaction times suggesting automatic processing, whereas bilinguals with a slower second-language reading rate did so in their first language but not in their second.
\end{abstract}

So-called balanced or fluent bilinguals often have been the object of research into cognitive processes underlying bilingualism. One reason for research interest in fluent bilinguals is that, although under ordinary communication conditions they may demonstrate equivalent speaking, listening, and reading skills in their two languages, some aspects of a specific skill may be relatively weaker in one of the languages. In this case, the fluent bilingual presents an opportunity to compare skilled and less skilled performance by the same individual. Such a comparison may provide an opportunity to study the cognitive processes underlying the activity in question while avoiding the usual confound due to individual differences (Baron \& Treiman, 1980). The present study was concerned with the reading performance of two types of fluent bilinguals in their first and second languages and examined the possibility of an association between reading skills and processes underlying retrieval from semantic memory. (The term fluent is used here because it emphasizes that, under normal

This research was supported by Grant FCAC-EQ-1163 awarded to Melvin K. Komoda, Edward Brussell, and Norman Segalowitz by the Quebec Ministery of Education. We thank Tannis Arbuckle-Maag, Melvin Komoda, and Barry McLaughlin for their constructive comments on earlier versions of this report. We would especially like to thank two anonymous reviewers for their helpful suggestions on an earlier version of this manuscript. Finally, we thank Meredith Alston, Daniel $F$ regeau, Debby Latimer, Helene Marceau, and Catherine Poulsen for their assistance at various stages of this project. Reprint requests may be sent to Norman Segalowitz, Psychology Department, Concordia University, 1455 de Maisonneuve Boulevard West, Montreal, Quebec H3G 1 M8, Canada. communication conditions, second-language performance is as skilled, i.e., fluent, as first-language performance without implying, as does the word "balanced," that first- and second-language skills are equal in all aspects and under all conditions.)

Many bilinguals normally fluent in their second language nevertheless read more slowly in that language than in their first language, for reasons not related to inadequate knowledge of vocabulary and syntax (Favreau, Komoda, \& Segalowitz, 1980; Favreau \& Segalowitz, 1982; Daitchman, Note 1). Some evidence suggests that such slowed second-language reading may arise, in part, from a reduced sensitivity to orthographic, syntactic, and semantic redundancies of the language (Favreau et al., 1980; Hatch, Polin, \& Part, 1974), which increases the reader's dependency on the purely visual information (Massaro, 1975). Slower secondlanguage reading has also been associated with differences in the fixation time of eye movements. Oller and Tullius (1973) reported that nonnative readers of English fixate for longer durations than do native readers, despite equivalent comprehension and a similar number of fixations and regressions per line. Since the duration of fixation presumably reflects informationprocessing time (Rayner, 1978), it appears that bilinguals require more time in the second language than in the first to process the same amount of printed information.

In recent years, a number of researchers (Hunt, 1978; Kahneman, 1973; LaBerge \& Samuels, 1974; Posner \& Snyder, 1975; Schneider \& Shiffrin, 1977; Shiffrin \& Schneider, 1977) have argued that cognitive activities may differ in the amount of attention and 
effort that they require. As a result of extensive practice and/or exposure, some operations require only minimal effort and are very fast, whereas others require considerable attention and are relatively slower. The former have been characterized as automatic (Shiffrin, Dumais, \& Schneider, 1981), and the latter as nonautomatic (Hunt, 1978), conscious (Posner \& Snyder, 1975), controlled (Shiffrin et al., 1981), or effortful (Hasher \& Zacks, 1979) processes. The distinction between operations that are automatic and those that are under strategic control has implications for second-language reading. A complex activity such as reading involves a number of highly practiced operations that are likely to be fairly automatic (LaBerge \& Samuels, 1974), such as those involved in direct word recognition without reliance on text structure. In addition, many operations are likely to be nonautomatic or under strategic control, such as when word meaning is derived from contextual information. Of course, depending upon the task demands, the amount of attention required to mobilize a strategy varies (Britton, Piha, Davis, \& Wehaussen, 1978). For many fluent bilinguals, some of the cognitive operations underlying reading may be fairly automatic in the first language, but the same operations may not be automatic in the second language. One level at which to look for such differences between the firstand second-language reading is in word recognition.

Several studies have indirectly addressed the role of automatic and controlled processes in retrieval by using lexical decision tasks in which subjects are required to decide whether a target letter string spells a word or a nonword (Schvaneveldt \& Meyer, 1973). Typically, reaction times for such decisions are faster if the target string is preceded by a semantically related word prime rather than by an unrelated word prime (Meyer \& Schvaneveldt, 1971; Schvaneveldt \& Meyer, 1973). This finding is known as the semantic facilitation effect, and both so-called automatic and controlled processes may be responsible for it. On the one hand, it has been shown that subjects' expectancies can influence the magnitude of the semantic facilitation effect (Neely, 1977; Tweedy, Lapinsky, \& Schvaneveldt, 1977), a finding generally taken to reflect the role of controlled attentional processes. On the other hand, the semantic facilitation effect has also been observed under conditions that minimized expectancies for a semantically associated prime-target word pair (Fischler, 1977), when subjects were unable to recall (Fischler \& Goodman, 1978) or even detect the prime (Fowler, Wolford, Slade, \& Tassinary, 1981) and when only $40 \mathrm{msec}$ elapsed between the prime and target words (Fischler \& Goodman, 1978). These findings are generally taken to reflect the operation of automatic processes.

Neely (1977) provided evidence for the usefulness of the automatic/controlled distinction in understanding the semantic facilitation effect. He used a lexical decision task in which the prime could be either a control string of $x s$ or the names of one of three semantic categories.
Subjects were informed of the category membership of the word target that followed each prime. For example, they were told that if the prime was BIRD, most often the following word would be the name of a type of bird (i.e., they were told to expect a semantically related word). They were also told that if the prime was BODY or BUILDING, most often the following word would be a part of a building or the body, respectively (i.e., they were told to expect a semantically unrelated word). Within each of these expectancy conditions, subjects were exposed to some unexpected word targets. For example, in the condition in which a related word was expected, the unexpected target was semantically unrelated to the prime (e.g., BIRD-DOOR); in the condition in which an unrelated word was expected, the unexpected target was semantically related to the prime (e.g., BODY-HEAD). Each expectancy condition was tested with short and long intervals between prime and target words.

Neely (1977) found that, on the one hand, with long intervals between the prime and the target, there was facilitation of reaction times to expected words and there was inhibition of reaction times to unexpected words, compared with what occurred in the control condition. This result was obtained regardless of the semantic relation between the prime and the word target, and was taken to reflect the operation of controlled processes mediating expectancies. On the other hand, with short prime-target intervals, reaction times to semantically related words were faster regardless of expectancy. This pattern of results was taken to reflect the operation of fast, automatic processes mediating highly practiced lexical search.

The idea that readers of different skill levels may differ in terms of their ability to process words automatically is found in the interactive-compensatory model of reading proposed by Stanovich and West (Stanovich, 1980; Stanovich, West, \& Feeman, 1981; West \& Stanovich, 1978). Basically, this model assumes that a deficit in any particular process (e.g., rapid automatic word recognition) will result in increased reliance on other information sources (e.g., contextual knowledge). Furthermore, the model assumes that skilled reading involves more rapid, context-free word recognition than does less skilled reading. Thus, the model predicts that highly practiced readers will process words quickly enough, under the appropriate conditions, to allow demonstration of facilitation effects before the slower acting contextual processes that would result in inhibition can exert their effect. The model also predicts that relatively less skilled readers will be more dependent on slower acting contextual processes, and hence will exhibit weaker facilitation effects and stronger inhibition effects under the appropriate conditions. With increasing practice, these patterns should shift in the direction of increased facilitation and decreased inhibition. In studies involving elementary school children of different grade levels and adults, Stanovich et al. 
(1981) and West and Stanovich (1978) obtained such a pattern of results.

The present research was concerned with whether, in the case of bilinguals, an association would be found between relatively slower reading rates in the second language and the absence of automatic processing during lexical decision and, conversely, an association between relatively fast reading rates in the second language and the presence of automatic processing. The present study used a modified version of Neely's (1977) lexical decision paradigm. There were two expectancy conditions: one in which subjects were biased to expect semantically related word pairs (expect-related) and another in which subjects were biased to expect semantically unrelated word pairs (expect-unrelated). Each expectancy condition was tested with two different stimulus onset asynchronies (SOAs): 200 and $1,150 \mathrm{msec}$. The bilingual subjects were presented with first- and second-language materials in each expectancy and SOA condition.

The subjects were screened for reading and listening proficiency in each of their two languages (see Favreau $\&$ Segalowitz, 1982). Only subjects who showed equivalently high levels of reading and listening comprehension in each of their two languages were retained for the study. In order to test the hypothesis that slowed reading is associated with less reliance on automatic lexical access, the subjects were separated into two groups: those who read both their first and second languages equally fast (equal-reading-rate subjects) and those who read their second language more slowly (unequal-readingrate subjects). Automatic processing would be indicated by evidence of a facilitation effect that was a function of the semantic relation between the prime and target words and not a function of expectancy. Nonautomatic or controlled processing would be indicated by evidence of a facilitation effect and an inhibition effect that were a function of expectancy and not of the semantic relation between the prime and the target words. It was hypothesized that this pattern of results would be obtained for all subjects in their first language, since all were highly practiced readers of their native language. It was expected, however, that if the absence of automatic operations is associated with slower reading, then the unequal-reading-rate subjects would show this pattern to a lesser extent in their second language than would the equal-reading-rate subjects.

\section{METHOD}

\section{Subjects}

The subjects were bilingual Anglophones (mother tongue English) and Francophones (mother tongue French) from Montreal, with French and English as a second language, respectively. They were screened using the procedures described in Favreau and Segalowitz (1982). Briefly, the subjects were asked to read standardized texts as quickly as possible and then to answer multiple-choice questions. Similarly, they were asked to listen to tape-recorded texts of compressed speech, the presentation rates of which were under their control. This provided for each subject and in each language a measure of optimal reading and listening rates and a measure of comprehension. To be included in this study, each subject had to satisfy the following criteria. First, his or her reading and listening comprehension in each language had to be at least $70 \%$. Second, to ensure a high level of bilingualism, the difference in comprehension scores between the two languages in both reading and listening had to be no greater than one question on the multiple-choice test (i.e., less than 12\%). Anglophones and Francophones who satisfied these requirements were then classified according to criteria regarding the relative speed of first- versus second-language reading. The equal-reading-rate subjects were those with a difference of less than $10 \%$ between the first- and second-language optimal reading rates ( 262 vs. 275 words/min, n.s.). The unequalreading-rate subjects were those with a difference of more than $10 \%$ between the first- and second-language optimal reading rates ( 318 vs. 234 words/min).

In all, 60 bilinguals were retained for the experiment. There were 30 Francophones and 30 Anglophones, with half of each language group meeting the equal-reading-rate criterion and half meeting the unequal-reading-rate criterion. The equal-readingrate and the unequal-reading-rate subjects had mean ages of 23.81 and 23.80 years, respectively. Approximately $90 \mathrm{bi}-$ linguals were screened to obtain the required sample, the majority of whom read more slowly in the second language than in the first. All subjects had normal or corrected-to-normal vision, as assessed by the Keystone School Vision Test. All subjects reported normal hearing. The subjects were paid $\$ 3.50$ per hour for their participation.

\section{Materials and Apparatus}

Experimental stimuli. The experimental stimuli consisted of four Fnglish and four French sets of 96 prime-target letterstring pairs. In each set, 48 of the primes were words and 48 consisted of a string of five os (blank prime). The blank primes used in baseline control trials served to compare performance on trials having word primes (Posner \& Snyder, 1975). In each set, 48 of the targets were words and 48 were pronounceable nonwords. Half the word and half the blank primes were followed by a word target, and the other half by pronounceable nonwords. Thus, each experimental set comprised 24 wordword, 24 word-nonword, 24 blank-word, and 24 blank-nonword prime-target pairs.

In each language, two sets were prepared for the expectrelated condition and two others for the expect-unrelated condition. The word primes in each set consisted of the names of four semantic categories. In each expect-related set, 20 of the 24 word targets were members of the four categories named by the word primes ( 5 from each). Thus, each expect-related set contained 20 word-word prime-target pairs in which the targets were semantically related to the primes (e.g., BIRD-ROBIN). The four remaining pairs contained target words drawn from a fifth category, one target word paired with each of the primes (e.g., BIRD-CARROT). In addition, within a given expectrelated set, 24 target words were drawn from the four categories named by the word primes and paired with blank control primes.

In each expect-unrelated set, 20 of the 24 word targets were members of four categories other than those named by the primes. Thus, each set contained 20 word-word prime-target pairs in which the targets were semantically unrelated to the primes (e.g., BIRD-CARROT). In these pairs, however, the targets for a given prime always came from the same unrelated category (e.g., BIRD-CARROT; BIRD-POTATO). The four remaining word-word pairs contained targets drawn from categories named by the prime. In addition, within a given expectunrelated set, 24 target words were drawn from the four main categories used in this condition and paired with blank control primes.

In each set, the word targets were chosen from among the best 13 representatives of their category of origin, as determined from semantic category norms for English- and French-speaking 
Quebecers (Favreau \& Segalowitz, Note 2). These words differed little in category membership strength and differed little in mean frequency of occurrence in their respective language. The words used in the two English-language expect-related sets had mean frequencies of occurrence of 28.4 and 34.5 , and those in the expect-unrelated sets had mean frequencies of occurrence of 28.1 and 30.9 per million according to Kučera and Francis (1967). The mean frequencies of occurrence of the two Frenchlanguage expect-related sets were 28.6 and 38.6 per million, and those of the expect-unrelated sets were 36.4 and 29.7 per million, according to Beaudot (Note 3). The Appendix shows the stimulus words used as targets in each language.

For each target word, a pronounceable nonword was derived by replacing one of its letters (or, when necessary, two of its letters) with a different one. The position of the changed letter varied randomly across words. Whenever possible, nonwords preserved the orthographic shape of the corresponding words. Thus, nonwords were equated to word targets with respect to their number of letters and syllables and as nearly as possible to their shapes in an attempt to force subjects to scrutinize each letter string in order to arrive at a lexical decision (Antos, 1979; James, 1975).

Practice stimuli. For each experimental set, a practice set containing 48 prime-target pairs was created using the same prime and target categories as those of the corresponding experimental set. Practice sets were prepared such that half the primes were words and the other half blank controls ("ooooo"). Similarly, half the targets were words and half were the derived pronounceable nonwords. In each practice set, the four possible prime category names occurred equally often. Hence, the practice sets corresponding to the expect-related experimental sets contained no semantically unrelated word-word pairs, and the practice sets for the expect-unrelated experimental sets contained no semantically related word-word pairs. To reduce the possibility of any effects due to repetition of items during practice (Scarborough, Cortese, \& Scarborough, 1977), the practice target words were selected from among the best 14 th to 24 th representatives of their category of origin (Favreau \& Segalowitz, Note 2).

All experimental and practice stimuli consisted of black letters on white $4 \times 6$ in. cards. Primes and targets were printed in lowercase and uppercase letters, respectively. The height and width of the average five-letter prime subtended visual angles of approximately 0.4 and $1.8 \mathrm{deg}$, respectively, at a viewing distance of $77.7 \mathrm{~cm}$. At this distance, the average six-letter target's height and width subtended visual angles of approximately 0.5 and $2.4 \mathrm{deg}$, respectively. An X served as a fixation mark. A four-channel Gerbrands tachistoscope was used to present the stimulus materials.

Design. Each subject participated in eight conditions of the experiment. Mother tongue (English, French) and reading tate (equal, unequal) were between-subject factors. Language (first, second), SOA (long, short) and expectancy (expect-related, expect-unrelated) were within-subject factors. The eight languageexpectancy-SOA condition combinations were blocked. The expectancy conditions manipulated the subject's expectancy regarding whether the word targets would be semantically related or unrelated to the categories named by the primes. In each condition, the subjects were exposed to five types of prime-target pairs: word-word semantically related, word-word semantically unrelated, blank-word semantically neutral, wordnonword, and blank-nonword.

Overall, each subject contributed 96 observations to each combination of the language, SOA, and expectancy variables. In each condition, the number of observations for each type of prime-target pair was as follows: 20 word-word expected, 4 word-word unexpected, 24 blank-word neutral, 24 wordnonword, and 24 blank-nonword. Within each condition, the different types of prime-target pairs were assigned randomly. The order of presentation of the language, SOA, and expectancy conditions was partially counterbalanced across subjects.
Procedure. The subjects were individually tested over four sessions of the experiment, each session being held on different days and each lasting approximately $40 \mathrm{~min}$. Throughout the experiment, the subjects were seated in a lighted, soundattenuated room. At the beginning of each session, the subjects received the general instructions in their mother tongue. These instructions introduced the subjects to the tachistoscopic events and informed them that the study was concerned with how quickly and accurately they could decide, in each of their two languages, whether a letter string formed a word. The general instructions emphasized that: (1) the subjects should fixate on the $X$ at the beginning of each trial; (2) a lowercase letter string consisting of either "ooooo" or a category name would immediately replace the X; (3) an uppercase letter string forming either an English (or French) word or a nonword would then appear; (4) the subjects should press one of the response keys to indicate their decision about the lexicality of the uppercase string; and (5) each trial would require full attention.

Within each session, the subjects were exposed to two experimental conditions, each preceded by two blocks of practice trials. Prior to the first block of practice trials, the subjects received instructions appropriate for the subsequent experimental condition in the language of that condition. In the expect-related condition, the subjects were given advance knowledge of the four possible prime and target categories and were told that on word-word presentations prime and target would be semantically related. Similarly, in the expect-unrelated condition, the subjects were given advance knowledge of the four possible primes and target categories and were told that on wordword presentations prime and target would be semantically unrelated. In this case, they were asked to memorize (until they could correctly report each association to the experimenter) which unrelated target category would accompany each priming category.

Each trial began with the verbal signal "READY" ("PRET"), which was followed by the $1,500-\mathrm{msec}$ fixation cross and then the prime word for $150 \mathrm{msec}$. Following the onset of the prime, there was either a short $(200-\mathrm{msec})$ or long $(1,150-\mathrm{msec})$ SOA to the onset of the target word, which then remained in view until the subject had indicated her or his lexical decision by pressing one of the response keys. The intertrial interval was 4 sec. Reaction times were recorded from the onset of the target to the keypress.

During the first block of 24 practice trials, the subjects received feedback regarding the accuracy and speed of their responses, but they received no feedback during the following block of 24 practice trials. Only the reaction times to correctly classified targets during experimental trials were included in the final data analyses.

There was a rest period of approximately $20 \mathrm{~min}$ between the completion of the first experimental condition and the beginning of the first block of practice trials for the second.

\section{RESULTS}

The mean correct reaction times of each subject on trials with word targets were subjected to a preliminary six-way analysis of variance with mother tongue (English, French) and group (equal, unequal) as between-subject factors and language (first, second), SOA (long, short), expectancy (expect-related, expect-unrelated), and relation (neutral, related, unrelated) as within-subject factors. The analysis yielded a significant mother tongue $x$ language $x$ expectancy $x$ relation interaction $[F(2,112)$ $=4.22, \mathrm{MSe}=3,004.3, \mathrm{p}<.05]$. However, post hoc Newman-Keuls tests performed on this four-way interaction indicated that the mother-tongue groups did not 
differ in terms of overall pattern. The interaction was due to the Francophones' reacting significantly faster to related words in the first language than to related words in the second language in the expect-related condition ( 553 vs. $602 \mathrm{msec}, \mathrm{p}<.01$ ), whereas the Anglophones did not ( 573 vs. $580 \mathrm{msec}, \mathrm{p}>.05$ ). There were no other significant differences between Anglophones and Francophones, and the mother-tongue factor did not interact with the group or SOA factors.

Because of the similarity in the pattern of results obtained by the two mother-tongue groups, the data were collapsed over the mother-tongue factor, resulting in 30 subjects in each reading-rate group. The mean correct reaction times on trials with word targets were subjected to two five-way analyses of variance, one across subjects (F1) and one across items (words) (F2). The factors in the subjects analysis were group (equal reading rate, unequal reading rate), SOA (long, short), language (first, second), expectancy (expectrelated, expect-unrelated), and relation (neutral, expected relation, unexpected relation), with repeated measures on the last four factors. In the items analysis, the repeated measures were on the group, SOA, and language factors. Table 1 presents the relevant mean reaction times together with their associated mean percentage error rates. Table 1 shows reaction times for trials with neutral primes and the facilitation $(+)$ or inhibition (-) effects on trials with related or unrelated primes (relative to the reaction times with neutral primes).

The most important result of these analyses was the significant five-way group $\mathrm{x}$ language $\mathrm{x}$ SOA $\mathrm{x}$ expectancy $x$ relation effect $[\mathrm{F} 1(2,116)=4.97, \mathrm{MSe}=2,824.9$, $\mathrm{p}<.01 ; \mathrm{F} 2(2,370)=3.89, \mathrm{MSe}=5,707.5, \mathrm{p}<.025]$. Post hoc Scheffé tests revealed that in the long-SOA condition, both groups exhibited facilitation for expected targets and inhibition for unexpected targets, in both their first and second languages and regardless of whether a related or unrelated target was expected. Also, both groups showed significant inhibitionless facilitation in their first language under the short-SOA condition.

In the second-language short-SOA condition, however, the equal-reading-rate and the unequal-readingrate groups differed in two important respects. First, although both groups showed significant facilitation for related targets in the expect-related condition, the mean reaction time of the equal-reading-rate group to a related target was significantly faster than the corresponding reaction time of the unequal-reading-rate group ( 575 vs. $628 \mathrm{msec}, \mathrm{p}<.001$ ) (the groups did not differ on mean reaction time to neutral targets: 651 vs. $656 \mathrm{msec}$ ). Second, in the expect-unrelated condition, again with short SOA, the equal-reading-rate group showed facilitation for related targets in the second language (639 msec for neutral targets vs. $543 \mathrm{msec}$ for related targets, $\mathrm{p}<.001)$, whereas the unequal-readingrate group did not (651 vs. $638 \mathrm{msec}, \mathrm{p}>.25$ ). Generally, the unequal-reading-rate subjects showed significantly slower reaction times to neutral second-language targets than to neutral first-language targets (overall means of 656 vs. $618 \mathrm{msec}, \mathrm{p}<.01$ in all cases except

Table 1

Mean Reaction Times (RT) (in Milliseconds), Mean Percentage of Errors (ME), and Facilitation (+) and Inhibition (-) Scores for Equal and Unequal Reading Rate Subjects to Word Targets in Each Language, Expectancy, and SOA Condition

\begin{tabular}{|c|c|c|c|c|c|c|c|c|c|c|}
\hline & & & \multicolumn{6}{|c|}{ Prime/Target Relation } & \multirow{2}{*}{\multicolumn{2}{|c|}{$\begin{array}{c}\text { Reaction Time } \\
\text { Difference }\end{array}$}} \\
\hline & & & \multicolumn{2}{|c|}{ Neutral (N) } & \multicolumn{2}{|c|}{ Related (R) } & \multicolumn{2}{|c|}{ Unrelated (U) } & & \\
\hline \multicolumn{3}{|c|}{ Condition } & RT & ME & RT & ME & RT & ME & $\mathbf{N}-\mathbf{R}$ & $\mathrm{N}-\mathrm{U}$ \\
\hline \multicolumn{11}{|c|}{ Equal Reading Rate Group } \\
\hline $\begin{array}{l}\text { L1 } \\
\text { L1 } \\
\text { L1 } \\
\text { L1 }\end{array}$ & $\begin{array}{l}\mathrm{xR} \\
\mathrm{xR} \\
\mathrm{xU} \\
\mathrm{xU}\end{array}$ & $\begin{array}{r}1150 \\
200 \\
1150 \\
200\end{array}$ & $\begin{array}{l}680 \\
649 \\
632 \\
647\end{array}$ & $\begin{array}{l}1.66 \\
2.97 \\
3.53 \\
2.95\end{array}$ & $\begin{array}{l}585 \\
575 \\
688 \\
547\end{array}$ & $\begin{array}{l}3.81 \\
3.22 \\
2.89 \\
3.75\end{array}$ & $\begin{array}{l}835 \\
665 \\
578 \\
622\end{array}$ & $\begin{array}{l}3.11 \\
1.67 \\
2.20 \\
2.10\end{array}$ & $\begin{array}{r}+95 * * \\
+74 * * \\
-56 * * \\
+100^{* *}\end{array}$ & $\begin{array}{l}-155^{* * *} \\
-16 \\
+54^{* *} \\
+25\end{array}$ \\
\hline $\begin{array}{l}\text { L2 } \\
\text { L2 } \\
\text { L2 } \\
\text { L } 2\end{array}$ & $\begin{array}{l}x R \\
x R \\
x U \\
x U\end{array}$ & $\begin{array}{r}1150 \\
200 \\
1150 \\
200\end{array}$ & $\begin{array}{l}661 \\
651 \\
641 \\
639\end{array}$ & $\begin{array}{l}3.00 \\
3.03 \\
4.71 \\
1.63\end{array}$ & $\begin{array}{l}570 \\
575 \\
719 \\
543\end{array}$ & $\begin{array}{l}4.64 \\
4.08 \\
2.53 \\
3.75\end{array}$ & $\begin{array}{l}789 \\
679 \\
566 \\
619\end{array}$ & $\begin{array}{l}1.36 \\
3.93 \\
3.09 \\
1.85\end{array}$ & $\begin{array}{l}+91 * * \\
+76^{* *} \\
-78^{*} \\
+96^{*}\end{array}$ & $\begin{array}{l}-128 * * \\
-28 \\
+75^{* *} \\
+20\end{array}$ \\
\hline \multicolumn{11}{|c|}{ Unequal Reading Rate Group } \\
\hline $\begin{array}{l}\text { L1 } \\
\text { L1 } \\
\text { L1 } \\
\text { L1 }\end{array}$ & $\begin{array}{l}x R \\
x R \\
x U \\
x U\end{array}$ & $\begin{array}{r}1150 \\
200 \\
1150 \\
200\end{array}$ & $\begin{array}{l}639 \\
619 \\
605 \\
610\end{array}$ & $\begin{array}{l}3.81 \\
1.31 \\
2.50 \\
1.67\end{array}$ & $\begin{array}{l}549 \\
544 \\
689 \\
530\end{array}$ & $\begin{array}{l}1.68 \\
3.21 \\
3.75 \\
5.56\end{array}$ & $\begin{array}{l}816 \\
626 \\
533 \\
606\end{array}$ & $\begin{array}{l}2.97 \\
2.69 \\
2.35 \\
3.06\end{array}$ & $\begin{array}{l}+90^{* *} \\
+75^{* *} \\
-84^{*} \\
+80^{* *}\end{array}$ & $\begin{array}{c}-177^{* *} \\
-7 \\
+72^{* *} \\
+4\end{array}$ \\
\hline $\begin{array}{l}\mathrm{L} 2 \\
\mathrm{~L} 2 \\
\mathrm{~L} 2 \\
\mathrm{~L} 2\end{array}$ & $\begin{array}{l}x R \\
x R \\
x U \\
x U\end{array}$ & $\begin{array}{r}1150 \\
200 \\
1150 \\
200\end{array}$ & $\begin{array}{l}662 \\
656 \\
653 \\
651\end{array}$ & $\begin{array}{l}2.78 \\
4.53 \\
3.33 \\
1.98\end{array}$ & $\begin{array}{l}591 \\
628 \\
716 \\
638\end{array}$ & $\begin{array}{l}5.00 \\
1.79 \\
1.57 \\
2.75\end{array}$ & $\begin{array}{l}794 \\
677 \\
606 \\
646\end{array}$ & $\begin{array}{l}1.67 \\
2.28 \\
1.67 \\
3.06\end{array}$ & $\begin{array}{l}+71 * * \\
+28 * * \\
-63 * \\
+13\end{array}$ & $\begin{array}{c}-132^{* *} \\
-21 \\
+47^{* *} \\
+5\end{array}$ \\
\hline
\end{tabular}

Note-Conditions were: $L 1=$ first language; $L 2=$ second language; $x R=$ expect-related $; x U=$ expect-unrelated; $1150=$ long SOA; $200=$ short SOA. $\quad *_{p}<.01 . \quad * *_{p}<.001$. 
in the long-SOA expect-related condition, in which the difference was not significant), whereas the equalreading-rate group did not ( $648 \mathrm{vs.} 652 \mathrm{msec}$ ).

Other effects that were significant in both the subjects and items analyses were: language $[F 1(1,58)=$ 8.82, MSe $=17,913.6, \mathrm{p}<.01 ; \mathrm{F} 2(1,370)=67.02$, $\mathrm{MSe}=6,409.3, \mathrm{p}<.001] ;$ relation $[\mathrm{F} 1(2,116)=226.09$, $\mathrm{MSe}=5,073.2, \mathrm{p}<.001 ; \mathrm{F} 2(2,370)=64.62, \mathrm{MSe}=$ $20,909.8, \mathrm{p}<.001]$; group $\mathrm{x}$ language $[\mathrm{F} 1(1,58)=$ $12.68, \mathrm{MSe}=17,913.6, \mathrm{p}<.001 ; \mathrm{F} 2(1,370)=123.57$, MSe $=5,509.8, p<.001] ;$ SOA $x$ expectancy $[F 1(1,58)$ $=7.82, \mathrm{MSe}=6,962.9, \mathrm{p}<.001 ; \mathrm{F} 2(1,370)=21.86$, $\mathrm{MSe}=5,721.6, \mathrm{p}<.001] ; \mathrm{SOA} \times$ relation $[\mathrm{F} 1(2,116)$ $=246.85, \mathrm{MSe}=4,002.4, \mathrm{p}<.001 ; \mathrm{F} 2(2,370)=107.27$, $\mathrm{MSe}=5,721.6, \mathrm{p}<.001] ;$ expectancy $\mathrm{x}$ relation $[\mathrm{F} 1(2,116)=133.16, \mathrm{MSe}=3,482.7, \mathrm{p}<.001 ; \mathrm{F} 2(2,370)$ $=24.91, \mathrm{MSe}=20,909.8, \mathrm{p}<.001] ;$ language $\mathrm{x} \mathrm{SOA} \mathrm{x}$ expectancy $[\mathrm{F} 1(1,58)=6.44, \mathrm{MSe}=5,040.0, \mathrm{p}<.05$; $\mathrm{F} 2(1,370)=6.77, \mathrm{MSe}=6,297.6, \mathrm{p}<.01]$; and language $x$ SOA $x$ relation $[\mathrm{F} 1(2,116)=4.72, \mathrm{MSe}=$ $3,339.3, \mathrm{p}<.05 ; \mathrm{F} 2(2,370)=4.45, \mathrm{MSe}=6,297.6$, $\mathrm{p}<.05]$.

The mean correct reaction times on trials with nonword targets were subjected to a similar five-way analysis of variance across subjects with the factors being group (equal reading rate, unequal reading rate), SOA (long, short), language (first, second), expectancy (expect-related, expect-unrelated), and relation (neutral, expected relation, unexpected relation), with repeated measures on the last four factors. In this case, nonwords were classified as being "related" or "unrelated" depending on whether they were derived from, and hence looked like, a related or unrelated word. Table 2 pre- sents the relevant mean reaction times together with their associated mean percentage error rates. Table 2 shows reaction times for trials with neutral primes and the facilitation $(+)$ or inhibition $(-)$ effects on trials with "related" or "unrelated" primes.

The most important results of this analysis were the following. There was a significant expectancy $\mathrm{x}$ relation interaction $[\mathrm{F}(2,116)=12.61, \mathrm{MSe}=2,638.3, \mathrm{p}<.001]$. Post hoc Scheffé tests revealed that in the expect-related condition, there was a significant facilitation effect $(+24$ msec, $p<.01)$, whereas there were no significant context effects in the expect-unrelated condition. There was also a significant $\mathrm{SOA} \times$ relation interaction $[\mathrm{F}(2,116)=5.66, \mathrm{MSe}=3,127.5, \mathrm{p}<.01]$. Post hoc Scheffé tests revealed that reaction times to neutral targets were significantly faster with the short SOA than with the long SOA ( 722 vs. $736 \mathrm{msec}, p<.01)$ and that there was a significant facilitation effect $(+20 \mathrm{msec}, \mathrm{p}<$ $.01)$ with the long SOA but not the short SOA. Finally, there was a significant group $x$ language $x$ relation interaction $[F(2,116)=3.55, \mathrm{MSe}=3,683.9, \mathrm{p}<.05]$. Post hoc tests did not reveal any significant differences between groups on any of the language $x$ relation combinations. However, the pattern seems to indicate that generally the unequal-reading-rate subjects were faster than the equal-reading-rate subjects in their first language, especially for "unexpected" targets, whereas the reverse was true in their second language, again especially for "unexpected" targets.

Other significant effects were: language $[F(1,58)=$ $11.25, \mathrm{MSe}=31,947.1, \mathrm{p}<.002] ;$ expectancy $[\mathrm{F}(1,58)$ $=4.50, \mathrm{MSe}=11,130.3, \mathrm{p}<.05] ;$ and group $\mathrm{x}$ language $[\mathrm{F}(1,58)=11.62, \mathrm{MSe}=31,947.1, \mathrm{p}<.002]$.

Table 2

Mean Reaction Times (RT) (in Milliseconds), Mean Percentage of Errors (ME), and Facilitation (+) and Inhibition (-) Scores for Equal and Unequal Reading Rate Subjects to Nonword Targets in Each Language, Expectancy, and SOA Condition

\begin{tabular}{|c|c|c|c|c|c|c|c|c|c|c|}
\hline & & & \multicolumn{6}{|c|}{ Prime/Target Relation } & \multirow{2}{*}{\multicolumn{2}{|c|}{$\begin{array}{l}\text { Reaction Time } \\
\text { Difference }\end{array}$}} \\
\hline & & & \multicolumn{2}{|c|}{ Neutral (N) } & \multicolumn{2}{|c|}{ Related (R) } & \multicolumn{2}{|c|}{ Unrelated (U) } & & \\
\hline \multicolumn{3}{|c|}{ Condition } & RT & ME & $\mathrm{RT}$ & $\mathrm{ME}$ & RT & $\mathrm{ME}$ & $\mathrm{N}-\mathrm{R}$ & $\mathrm{N}-\mathrm{U}$ \\
\hline \multicolumn{11}{|c|}{ Equal Reading Rate Group } \\
\hline $\begin{array}{l}\text { L1 } \\
\text { L1 } \\
\text { L1 } \\
\text { L1 }\end{array}$ & $\begin{array}{l}\mathrm{xR} \\
\mathrm{xR} \\
\mathrm{xU} \\
\mathrm{xU}\end{array}$ & $\begin{array}{r}1150 \\
200 \\
1150 \\
200\end{array}$ & $\begin{array}{l}772 \\
740 \\
715 \\
719\end{array}$ & $\begin{array}{l}2.20 \\
3.27 \\
2.49 \\
4.31\end{array}$ & $\begin{array}{l}760 \\
743 \\
699 \\
711\end{array}$ & $\begin{array}{l}2.72 \\
1.92 \\
1.67 \\
2.50\end{array}$ & $\begin{array}{l}720 \\
729 \\
717 \\
731\end{array}$ & $\begin{array}{l}0.00 \\
1.67 \\
2.88 \\
5.16\end{array}$ & $\begin{array}{r}+12 \\
-3 \\
+16 \\
+8\end{array}$ & $\begin{array}{r}+52 \\
+11 \\
-2 \\
-11\end{array}$ \\
\hline $\begin{array}{l}\mathrm{L} 2 \\
\mathrm{~L} 2 \\
\mathrm{~L} 2 \\
\mathrm{~L} 2\end{array}$ & $\begin{array}{l}\mathrm{xR} \\
\mathrm{xR} \\
\mathrm{xU} \\
\mathrm{xU}\end{array}$ & $\begin{array}{r}1150 \\
200 \\
1150 \\
200\end{array}$ & $\begin{array}{l}757 \\
741 \\
721 \\
715\end{array}$ & $\begin{array}{l}3.87 \\
3.00 \\
1.71 \\
3.54\end{array}$ & $\begin{array}{l}755 \\
736 \\
724 \\
715\end{array}$ & $\begin{array}{r}2.44 \\
6.25 \\
.83 \\
2.50\end{array}$ & $\begin{array}{l}711 \\
723 \\
723 \\
728\end{array}$ & $\begin{array}{r}.83 \\
0.00 \\
4.25 \\
1.59\end{array}$ & $\begin{array}{r}+22 \\
+5 \\
-3 \\
0\end{array}$ & $\begin{array}{r}+46 \\
+18 \\
-2 \\
-13\end{array}$ \\
\hline \multicolumn{11}{|c|}{ Unequal Reading Rate Group } \\
\hline $\begin{array}{l}\text { L1 } \\
\text { L1 } \\
\text { L1 } \\
\text { L1 }\end{array}$ & $\begin{array}{l}\text { XR } \\
\text { xR } \\
\text { xU } \\
\text { xU }\end{array}$ & $\begin{array}{r}1150 \\
200 \\
1150 \\
200\end{array}$ & $\begin{array}{l}713 \\
690 \\
686 \\
684\end{array}$ & $\begin{array}{l}2.31 \\
4.93 \\
4.08 \\
2.67\end{array}$ & $\begin{array}{l}694 \\
697 \\
684 \\
699\end{array}$ & $\begin{array}{l}5.34 \\
2.15 \\
3.33 \\
3.33\end{array}$ & $\begin{array}{l}690 \\
657 \\
664 \\
696\end{array}$ & $\begin{array}{r}.83 \\
0.00 \\
1.84 \\
2.00\end{array}$ & $\begin{array}{r}+19 \\
-7 \\
+2 \\
-15\end{array}$ & $\begin{array}{l}+23 \\
+33 \\
+22 \\
-12\end{array}$ \\
\hline $\begin{array}{l}\mathrm{L} 2 \\
\mathrm{~L} 2 \\
\mathrm{~L} 2 \\
\mathrm{~L} 2\end{array}$ & $\begin{array}{l}\mathrm{xR} \\
\mathrm{xR} \\
\mathrm{xU} \\
\mathrm{xU}\end{array}$ & $\begin{array}{r}1150 \\
200 \\
1150 \\
200\end{array}$ & $\begin{array}{l}764 \\
744 \\
757 \\
743\end{array}$ & $\begin{array}{l}4.44 \\
3.46 \\
2.39 \\
5.73\end{array}$ & $\begin{array}{l}726 \\
763 \\
741 \\
740\end{array}$ & $\begin{array}{l}5.00 \\
3.43 \\
4.17 \\
6.67\end{array}$ & $\begin{array}{l}739 \\
766 \\
759 \\
775\end{array}$ & $\begin{array}{r}3.33 \\
.83 \\
2.17 \\
4.08\end{array}$ & $\begin{array}{r}+18 \\
-19 \\
+16 \\
+3\end{array}$ & $\begin{array}{r}+25 \\
-22 \\
-2 \\
-32\end{array}$ \\
\hline
\end{tabular}

Note-Conditions were: $L 1=$ first language; $L 2=$ second language; $x R=$ expect-related; $x U=$ expect-unrelated; $1150=$ long SOA; $200=$ short $S O A$. 


\section{DISCUSSION}

The first result to consider is the pattern of reaction times to first-language targets shown in Table 1. This pattern replicated the effect reported by Neely (1977) and indicates that the distinction between automatic and controlled lexical access may be extended to bilinguals with English and French as a first language. With the long SOA, there was a facilitation effect for expected word targets only, whether or not they were semantically related to the prime. Also, there was an inhibition effect for unexpected word targets (i.e., for related words in the expect-unrelated condition and for unrelated words in the expect-related condition). This is the pattern associated with a nonautomatic process, and it presumably reflects the operation of processes under strategic control, such as those initiated by the prime and guided by expectancies. In contrast, with the short SOA, there was a facilitation effect for related words regardless of expectancy and no inhibition effect for unrelated words. This is the pattern associated with automatic processing. Presumably, it reflects the operation of the relatively faster process of accessing the target word before the slower strategically controlled operations initiated by the prime are able to influence lexical decision. Thus, with the long SOA, the facilitation effect was determined by expectancy, whereas with the short SOA, the facilitation effect was determined by relatedness.

The second result bears directly on the association between automatic processing in lexical access and relative speed of second-language reading. In the short-SOA condition, the equal-reading-rate subjects showed a facilitation effect for related targets and an absence of inhibition for unrelated targets in both the first and second languages, regardless of which kind of target was expected. This is the pattern described as being associated with automatic processing. In contrast, the unequalreading-rate subjects produced a significantly smaller facilitation effect for related targets in the expectrelated condition and no facilitation effect for related targets in the expect-unrelated condition. Thus, the results indicate a strong contribution of automatic mechanisms in the processing of second-language targets by equal-reading-rate subjects and a significantly weaker contribution of automatic mechanisms in the processing of second-language targets by unequal-readingrate subjects.

The finding of reduced automatic processing by the unequal-reading-rate subjects in their second language compared with that in their first is of special interest because these bilinguals possess fluent and native-like language skills under normal conditions of listening, reading, and speaking. The present data do not address why they differed from the equal-reading-rate subjects in the way that they did. The answer may simply be that they differed in the amount of practice that they had had in reading their second language. Although we have no direct data bearing on this issue, we did find that the equal-reading-rate bilinguals had been schooled longer in their second language than had the unequal-readingrate bilinguals, even though both groups attained full fluency (reported in Favreau \& Segalowitz, 1982). If automaticity results from extended practice, then the equal-reading-rate bilinguals were favored. But exposure to the language and to the activity of reading as such were probably not the only deciding factors. After all, the unequal-reading-rate bilinguals displayed a pattern of automatic processing with first-language material, they were highly skilled readers in both languages, and they could speak and understand the second language fluently.

Two different approaches might be taken to explain this difference. On the one hand, perhaps second-language operations required more processing capacity or resources than did first-language operations for unequalreading-rate subjects but not for equal-reading-rate subjects. This view would be consistent with the suggestion of Shiffrin et al. (1981) that nonautomaticity of performance reflects utilization of one's limited processing capacity. It would also be consistent with a suggestion by Dornic (1980) that for many bilinguals there is less spare processing capacity available when they are working in the second language. On the other hand, the difference may lie in the degree to which the component cognitive operations were integrated or coordinated for processing in a second-language situation, not in the amount of processing capacity each operation required (cf. Neisser, Note 4). This view would be consistent with the finding that during their formative years, the unequal-reading-rate subjects had received less practice in reading the second language.

It is interesting to compare the present results with those of other studies using a similar paradigm with groups of subjects differentiated by reading skill. For example, Eisenberg and Becker (1982) presented two groups of readers a lexical decision task with neutral, related, or unrelated primes using long-SOA $(1,050 \mathrm{msec})$ and expect-related conditions. They found that skilled readers (those who read easy and difficult texts at about the same rate) showed a large facilitation effect for related targets and a small inhibition effect for unrelated targets. This pattern of facilitation dominance was interpreted in terms of Becker's (1980) verification model. According to this view, the skilled readers were using a "prediction strategy" whereby the prime cued the subject to be prepared for a well-defined set of potential targets without producing inhibition for unpredicted targets. In contrast, they found that less skilled readers (those who read difficult texts more slowly than easy texts) showed a small facilitation effect for related targets and a large inhibition effect for unrelated targets. This pattern of inhibition dominance was interpreted to reflect an "expectancy strategy" whereby the prime cued a general elimination of readiness for potential nontargets without provid. ing facilitation for specific potential targets.

Our unequal-reading-rate subjects appeared to function like relatively skilled readers in their first language 
but like less skilled readers in their second language. Thus, from the results of Eisenberg and Becker (1982), one would expect that, in the long-SOA expect-related condition, unequal-reading-rate subjects would demonstrate more facilitation dominance in their first language than in their second language and more inhibition dominance in their second language than in their first. Furthermore, one would expect that equal-reading-rate subjects would show facilitation dominance in both their first and second languages. Yet, as Becker (1980) pointed out, many factors may influence the pattern of dominance observed. Our subjects were instructed to expect a related word most of the time, whereas Eisenberg and Becker's (1982) subjects were instructed to generate (predict) category member names upon seeing a category name prime. Also, our subjects had to deal with fewer categories but more category member names for each category than did their subjects. Such factors might favor the use of an expectation strategy rather than a prediction strategy, resulting in inhibition dominance.

When our results are looked at in terms of facilitation and inhibition dominance, it can be seen that they differ from the Eisenberg and Becker (1982) results in several ways. First, it can be seen from Table 1 that our subjects demonstrated both significant and substantial (e.g., over $50-\mathrm{msec}$ ) facilitation and inhibition. Eisenberg and Becker indicated that their subjects showed either substantial facilitation or substantial inhibition, but not both. We therefore further analyzed our data to see whether the amount of facilitation differed significantly from the amount of inhibition, despite the fact that each was significant. For this purpose, a three-way analysis of variance was conducted on the scores reflecting the magnitude of facilitation (neutral reaction time minus related reaction time) and inhibition (unrelated reaction time minus neutral reaction time) in the expect-related long-SOA condition. The factors were group (equal reading rate, unequal reading rate), language (first, second), and effect (facilitation, inhibition), with repeated measures over the last two factors. This analysis yielded a significant result for effect $[F(1,58)=21.61$, $\mathrm{MSe}=10,552.5, \mathrm{p}<.001]$, indicating that the mean inhibition effect $(148 \mathrm{msec})$ was significantly greater than the mean facilitation effect $(86 \mathrm{msec})$. In this respect, the present data resemble the inhibition dominance patterns reported by Becker (1980, Experiment 2), Fischler and Bloom (1979), and Neely $(1976,1977)$. In addition, there was a significant language effect $[\mathrm{F}(1,58)=4.23, \mathrm{MSe}=8,011.6, \mathrm{p}<.05]$, indicating that facilitation and dominance effects were larger in the first-language than in the second-language condition. Of particular interest to the present discussion, however, was the lack of significant group differences or interaction effects (all $F_{s}<1$ ). Specifically, the unequalreading-rate subjects did not show evidence of a greater inhibition effect in their second language than in their first language or than the inhibition effects of the equalreading-rate subjects, although that is what would be predicted for slow readers by the verification model
(Eisenberg \& Becker, 1982). A two-process model such as the one proposed by Posner and Snyder (1975) does predict the general facilitation and inhibition context effects obtained here. However, such a model also predicts that context effects should, if anything, be greater for second-language targets for unequal-reading-rate subjects. This is because these subjects were poorer readers in their second language, and therefore should be more dependent upon semantic context (West \& Stanovich, 1982). Thus one would expect increased inhibition for unexpected unrelated targets. This was not obtained. In fact, there was a significant effect in the opposite direction: Context effects were larger overall for first-language materials, and the unequal-readingrate group showed a larger inhibition effect $(-177 \mathrm{msec})$ for unexpected unrelated first-language material than for the corresponding second-language material $(-132 \mathrm{msec})$.

In general, the pattern of reaction times to word targets was consistent with the idea that the unequalreading-rate subjects were unable to take advantage of semantic context to the same extent as the equal-readingrate subjects when functioning in their second language. Specifically, this manifested itself as reduced automatic processing, as reflected in the lowered inhibitionless facilitation effects for semantically related targets in the short-SOA condition. It does not appear from these data, however, that the unequal-reading-rate subjects were correspondingly more dependent on controlled or strategic processing, since the inhibition effects observed with the long SOA were not larger than those obtained for first-language targets or than the inhibition effects exhibited by the equal-reading-rate subjects.

The pattern of reaction times to nonwords resembled findings reported by Antos (1979), Neely $(1976,1977)$, and Schvaneveldt and McDonald (1981) in that, with a long SOA, there was general facilitation of reaction time to nonwords primed with a word regardless of whether the nonword looked like a semantically related word or not $(+13 \mathrm{msec}$ for "expected" and $+20 \mathrm{msec}$ for "unexpected" nonwords). With the short SOA, however, there was neither facilitation nor inhibition $(-4 \mathrm{msec}$ ) (Antos, 1979, reported inhibition for "unrelated" nonwords at a short SOA). Thus, in general, the present data do show context effects for nonwords, mainly facilitation. However, the three-way group $x$ language $x$ relation interaction also suggested that there were differences between the two groups of bilinguals on nonwords. In the first-language condition, the unequal-reading-rate group appeared to be significantly faster than the equal-reading-rate group with "unexpected" nonwords, whereas in the second-language condition, they were slower. This pattern resembles the relative-reading. rate differences of the two groups of subjects. The unequal-reading-rate subjects actually read their first language somewhat faster than did the equal-reading rate group (see Favreau \& Segalowitz, 1982, for a discussion of this) and read their second language more slowly. To the extent that such context effects for nonwords may indicate the existence of general activa- 
tion of linguistic information processing by word primes that is not related to semantic relationships, as suggested by Schvaneveldt and McDonald (1981), the interaction effect with the group factor may indicate that the benefits associated with the operation of these general processes are nevertheless a function of practice and skill specific to reading a particular language.

Taken together, the data of the present study can be seen to be only partly consistent with the two-process theory as elaborated in the interactive-compensatory model of reading. Consistent with predictions of this model, the less skilled readers showed less automaticity (i.e., a reduced pattern of inhibitionless facilitation) in their second language than did the more skilled readers or than they themselves did in their first language. However, these same less skilled readers did not show the predicted larger context effects in their second language. That is, there was no evidence of compensatory reliance on slower contextual processing in their second language. It is important to remember, of course, that unlike the populations studied by Stanovich et al. (1981) and West and Stanovich (1978), the unequalreading-rate subjects read in each language at rates well within the range of normal monolingual readers (200300 words/min, Gibson \& Levin, 1975). With this in mind, it would appear that the study of second-language reading may provide additional interesting ground for developing our understanding of the processes underlying reading development in general.

\section{REFERENCE NOTES}

1. Daitchman, M. Reading and listening comprehension of fluent bilinguals in the native and second languages. Unpublished manuscript, Concordia University, Montreal, 1976.

2. Favreau, M., \& Segalowitz, N. Semantic category norms for the French and English Quebec populations. Paper presented at the meeting of the American Psychological Association, Montreal, September 1980.

3. Beaudot, J. Fréquence d'usage des mots de la langue francaise. Unpublished manuscript, Université de Montreál, 1975.

4. Neisser, U. Skills, affordances, and divided attention. Address delivered to the Canadian Psychological Association, Montreal, June 1982.

\section{REFERENCES}

Antos, S. J. Processing facilitation in a lexical decision task. Journal of Experimental Psychology: Human Perception and Perfor. mance, 1979, 5, 527-545.

Baron, J., \& Treiman, R. Some problems in the study of differences in cognitive processes. Memory \& Cognition, 1980, 8, 313-316.

Becker, C. A. Semantic context effects in visual word recognition: An analysis of semantic strategies. Memory \& Cognition, 1980, 8, 493-512.

Britton, B. K., Piha, A., Davis, J., \& Wehaussen, E. Reading and cognitive capacity usage: Adjunct question effects. Memory \& Cognition, 1978, 6, 266-273.

Dornic, S. Language dominance, spare capacity and perceived effect in bilinguals. Ergonomics, 1980, 23, 369-377.

Eisengerg, P., \& Becker, C. Semantic context effects in visual word recognition, sentence processing, and reading: Evidence for semantic strategies. Journal of Experimental Psychology: Human Perception and Performance, 1982, 8, 739-756.
Favreau, M., Komoda, M. K., \& Segalowitz, N. Second language reading: Implications of the word superiority effect in skilled bilinguals. Canadian Journal of Psychology, 1980, 4, 370-381.

Favreau, M., \& Segalowitz, N. Second language reading in fluent bilinguals. Applied Psycholinguistics, 1982, 3, 329-341.

Fischler, I. Associative facilitation without expectancy in a lexical decision task. Journal of Experimental Psychology: Human Perception and Performance, 1977, 3, 18-26.

Fischler, I., \& Bloom, P. A. Automatic and attentional processes in the effects of sentence contexts on word recognition. Journal of Verbal Learning and Verbal Behavior, 1979, 18, 1-20.

Fischler, I., \& Goodman, G. O. Latency of associative activation in memory. Journal of Experimental Psychology: Human Perception and Performance, 1978, 4, 455-470.

Fowler, C. A., Wolfond, G., Slade, R., \& Tassinary, L. Lexical access with and without awareness. Journal of Experimental Psychology: General, 1981, 110, 341-363.

Gibson, E., \& Levin, H. The psychology of reading. Cambridge, Mass: MIT Press, 1975.

Hasher, L., \& Zacks, R. T. Automatic and effortful processes in memory. Journal of Experimental Psychology: General, 1979, 108, 356-388.

Hatch, E., Polin, P., \& Part, S. Acoustic scanning and syntactic processing: Three reading experiments with first and second language learners. Journal of Reading Behavior, 1974, 6, 275-285.

Hunt, E. Mechanics of verbal ability. Psychological Review, 1978, 85, $109-130$.

JAMEs, C. T. The role of semantic information in lexical decisions. Journal of Experimental Psychology: Human Perception and Performance, 1975, 1, 130-136.

Kahneman, D. Attention and effort. Englewood Cliffs, N.J: Prentice-Hall, 1973.

KuČera, H., \& Francis, W. N. Computational analysis of present-day American English. Providence, R.I: Brown University Press, 1967.

LABErge, D., \& SAmuels, S. J. Toward a theory of automatic information processing in reading. Cognitive Psychology, 1974, 6, 293-323.

Massaro, D. W. Primary and secondary recognition in reading. In D. W. Massaro (Ed.), Understanding language: An information processing analysis of speech, reading, and psycholinguistics. New York: Academic Press, 1975.

Meyer, D. E., \& Schvaneveldt, R. W. Facilitation on recognizing pairs of words: Evidence of a dependence between retrieval operations. Journal of Experimental Psychology, 1971, 90, 227-234.

NeELy, J. H. Semantic priming and retrieval from lexical memory: Evidence for facilitatory and inhibitory processes. Memory \& Cognition, 1976, 4, 648-654.

NeELy, J. H. Semantic priming and retrieval from lexical memory: Roles of the inhibitionless spreading activation and limitedcapacity attention. Journal of Experimental Psychology: General, 1977, 106, 226-254.

Oller, J. W., JR., \& Tullius, J. Reading skills of non-native speakers of English. International Review of Applied Linguistics, 1973, 11, 69-80.

Posne R, M. I., \& SNyde R, C. R. R. Attention and cognitive control. In R. C. Solso (Ed.), Information processing and cognition: The Loyola Symposium. Hillsdale, N.J: Erlbaum, 1975.

RAYNER, K. Eye movements in reading and information processing. Psychological Bulletin, 1978, 85, 618-660.

Scarborough, D. L., Cortese, C., \& Scanborough, H. S. Frequency and repetition effects in lexical memory. Journal of Experimental Psychology: Human Perception and Performance, 1977, 3, 1-17.

Schneider, W., \& Shiffrin, R. M. Controlled and automatic processing: I. Detection, search and attention. Psychological Review, 1977, 84, 1-66.

Schvaneveldt, R. W., \& McDonald, J. E. Semantic context 
and the encoding of words: Evidence for two modes of stimulus analysis. Journal of Experimental Psychology: Human Perception and Performance, 1981, 7, 673-687.

Schvaneveldt, R. W., \& Meyer, D. E. Retrieval and comparison processes in semantic memory. In S. Kornblum (Ed.), $A t$ tention and performance IV. New York: Academic Press, 1973.

Shiffrin, R. M., Dumais, S., \& Schneider, W. Characteristics of automatism. In L. Long \& A. Baddeley (Eds.), Attention and performance IX. Hillsdale, N.J: Erlbaum, 1981.

Shiffrin, R. M., \& Schneider, W. Controlled and automatic processing: II. Perceptual learning, automatic attending and a general theory. Psychological Review, 1977, 84, 127-190.

Stanovich, K. E. Toward an interactive-compensatory model of individual differences in the development of reading fluency. Reading Research Quarterly, 1980, 16, 32-71.
Stanovich, K. E., West, R., \& Feeman, D. A longitudinal study of sentence context effects in second-grade children: Tests of an interactive-compensatory model. Journal of Experimental Child Psychology, 1981, 32, 185-199.

Tweedy, J. R., Lapinsky, R. H., \& Schvaneveldt, R. W. Semantic-context effects on word recognition: Influence of varying the proportion of items presented in an appropriate context. Memory \& Cognition, 1977, 1, 84-89.

West, R. F., \& Stanovich, K. E. Automatic contextual facilitation in readers of three ages. Child Development, 1978, 49, 717-727.

West, R. F., \& Stanovich, K. E. Source of inhibition in experiments on the effect of sentence context on word recognition. Journal of Experimental Psychology: Learning, Memory, and Cognition, 1982, 8, 385-399.

\section{APPENDIX}

Stimulus Words

Expect-Related Condition: Expected Words (Related to Prime)

English: BLUE, BROWN, RED, WHITE, YELLOW, BEIGE, BLACK, GRAY, ORANGE, PINK, PURPLE ALCOHOL, JUICE, MILK, SODA, TEA, BEER, COFFEE, COKE, GIN, WATER, WINE

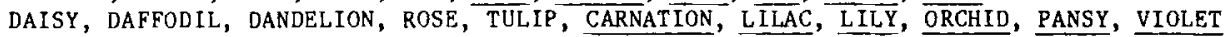
ANT, BEETLE, COCKROACH, MOSQUITO, SPIDER, BEE, FLY, LADYBUG, ROACH, WASP, WORM BEAR, CAT, COW, HORSE, TIGER, DOG, ELEPHANT, LION, MOUSE, PIG, RABBIT DRESS, PANTS, SHIRT, SHOES, SKIRT, BLOUSE, COAT, RAT, JACXET, SOCKS, SWEATER NYLON, SATIN, SILK, SYNTHETIC, WOOL, COTTON, DENIM, JEAN, LINEN, POLYESTER, RAYON BASEBALL, FOOTBALL, JOGGING, SKIING, VOLLEYBALL, GOLF, HOCXEY, TENNIS, RUNNING, SOCCER, SWIMMING

French: ANANAS, FRAISE, ORANGE, POIRE, POMME, BANANE, BLUET, CERISE, CITRON, PRUNE, RAISIN COUTEAU, RABOT, SCIE, MARTEAU, TOURNEVIS, CISEAU, CLE, CLOU, EQUERRE, HACHE, PINCE ASTRONOMIE, CHIMIE, MEDECINE, PHYS IQUE, SANTTE, BIOLOGIE, EDUCATION, HUMAINE, NATURELLE, POLITIQUE, PURE CORDUROY, FLANELLE, LAINE, SOIE, VELOUR, ACRYLIQUE, DENIM, LIN, NYLON, POLYESTER, SATIN BAGUE, BRACELET, CHAINE, COLLIER, MONTRE, ANNEAU, BOUCLE, BRELOQUE, JONC, MEDAILLON, PENDENTIF BOTILLON, BOTTE, ESPADRILLE, SABOT, SANDALE, BOTTINE, CHAUSETTE, MOCASSIN, PANTOUFLE, PATIN, SOULIER MUGUET, PENSEE, PIVOINE, TULIPE, VIOLETTE, JONQUILLE, LILAS, LYS, OEILLET, P ISSENLIT, ROSE CHAISE, DIVAN, FAUTEUIL, PUPITRE, TABLE, ARMOIRE, BUFFET, BUREAU, COMMODE, LIT, SOFA

Expect-Unrelated Condition: Expected Words (Unrelated to Prime)

English: BUDGIE, CROW, EAGLE, ROBIN, SPARROW, CANARY, HAWK, OWL, PARROT, PIGEON, SWALLOW MOCCASIN, SANDAL, SHOE, SLIPPER, SNEAKER, BOOT, CLOG, LOAFERS, RUBBERS, SKATE, SOCKS BED, BUREAU, CHAIR, COUCH, LAMP, BOOKCASE, DESK, DRESSER, SOFA, STOOL, TABLE DAK, MAPLE, PINE, SPRUCE, WILLOW, BIRCH, ELM, EVERGREEN, FIR, POPLAR, REDWOOD BASS, COD, SALMON, SHARK, TROUT, DOLPHIN, HALIBUT, PERCH, PIKE, SOLE, TUNA BANANA, GRAPE, MELON, ORANGE, PEACH, APPLE, CHERRY, LEMON, PEAR, PINEAPPLE, PLUM BROCCOLI, CABBAGE, CARROT, POTATO, TURNIP, CELERY, CORN, CUCUMBER, LETTUCE, PEA, TOMATO BICYCLE, BIKE, BUS, CAR, TRAIN, AIRPLANE, BOAT, METRO, TRUCK, PLANE, VAN

French: CHIEN, LION, LOUP, OURS, VACHE, CHAT, CHEVAL, LAPIN, MOUTON, SOURIS, TIGRE BLEU, GRIS, JAUNE, ROSE, VERT, BLANC, BRUN, NOIR, ORANGE, ROUGE, VIOLET CORBEAU, HIRONDELLE, MOINEAU, PERRUCHE, SERIN, AIGLE, GOELAND, MOUETTE, PERROQUET, PIGEON, PINSON BLOUSE, CHAPEAU, CHEMISE, MANTEAU, ROBE, BAS, CHANDAIL, GILET, PANTALON, SOULIER, VESTON CEDRE, ERABLE, PIN, POMMIER, SAPIN, BOULEAJ, CHENE, MERISIER, ORME, PEUPLIER, SAULE CAROTTE, CELERI, CHOU, LAITUE, NAVET, BROCOLI, CONCOMBRE, FEVE, PATATE, PIMENT, TOMATE BRAS, CERVEAU, COEUR, JAMBE, TETE, BOUCHE, MAIN, NEZ, OREILLE, PIED, TRONC BALEINE, BROCHET, MORUE, REQUIN, SAUMON, ACHIGAN, CARPE, DORE, PERCHAUDE, SOLE, THON

Expect-Related Condition: Unexpected Words (Unrelated to Prime)

English: DINGY, CANOE, SHIP, YACHT, ARCHITECT, BANKER, DENTIST, TEACHER

French: CHALET, IGLOU, LOGEMENT, TENTE, COURSE, NATATION, SRI, TENNIS

Expect-Unrelated Condition: Unexpected Words (Related to Prime)

English: BOMB, COAL, COTTAGE, EMERALD, FRAJD, IRON, MEDICINE, WATCH

French: ABEILle, ACIER, AVOCAT, CANCER, CARGO, COUTEAU, LIQUeUR, PETROLE

Note-Underlined words were preceded by the control prime ("ooooo"). 